\title{
Comparison of Mucosal and Intramuscular Immunization against SARS-CoV-2 with Replication- Defective and Replicating Single-cycle Adenovirus Vaccines
}

Haley E. Mudrick1, Erin B. McGlinch², Brian J. Parrett ${ }^{2,3}$, Jack R. Hemsath², Mary E. Barry $^{4}$, Jeffrey D. Rubin ${ }^{3}$, Chisom Uzendu ${ }^{3}$, Michael J. Hansen ${ }^{5}$, Courtney L. Erskine $^{5}$, Virginia P. VanKeulen ${ }^{5}$, Aleksandra Drelich ${ }^{6}$, Chien-Te Kent Tseng ${ }^{6,7}$, Shane Massey ${ }^{8}$, Madiha Fida ${ }^{4}$, Gina A. Suh ${ }^{4}$, Tobias Peikert ${ }^{5,9,10}$. Matthew S. Block $^{5,9}$, Gloria R. Olivier ${ }^{11}$, and Michael A. Barry ${ }^{4,5,12 \#}$

${ }^{1}$ Molecular Pharmacology and Experimental Therapeutics (MPET) Graduate Program

${ }^{2}$ Graduate Research Education Program (GREP)

${ }^{3}$ Virology and Gene Therapy (VGT) Graduate Program

${ }^{4}$ Department of Medicine, Division of Infectious Diseases

${ }^{5}$ Department of Immunology

${ }^{9}$ Department of Medical Oncology

$18{ }^{10}$ Department of Medicine, Division of Pulmonary Care

${ }^{11}$ Mayo Clinic Ventures

${ }^{12}$ Department of Molecular Medicine Mayo Clinic, Rochester, MN

${ }^{6}$ Department of Microbiology and Immunology

${ }^{7}$ Center of Biodefense and Emerging Disease

${ }^{8}$ Institutional Office or Regulated Nonclinical Studies

\#Correspondence to: Michael A. Barry, PhD.

Running Title: Mucosal and Systemic Single-cycle COVID-19 Vaccine 


\section{Abstract}

39 SARS-CoV-2 enters the body at mucosal surfaces, such as the nose and lungs. These

40 events involve a small number of virions at these mucosal barriers and are therefore a

41 strategic point to stop a COVID-19 infection before it starts. Despite this, most vaccines

42 against COVID-19 are being injected into the muscle where they will not generate the

43 highest levels of mucosal protection. The vaccines that are approved for use in humans

44 are all replication-defective (RD) mRNA, DNA, or adenovirus (Ad) vaccines that do not

45 amplify antigen transgenes. We developed single cycle adenovirus (SC-Ad) vectors that

46 replicate antigen genes up to 10,000 -fold in human cells, but that are disabled from

47 producing infectious Ad particles. We show here that SC-Ad expressing the full-length

48 SARS-CoV-2 spike protein produces 100 -fold more spike protein than a matched RD-Ad-

49 Spike vector. When Ad-permissive hamsters were immunized with these vaccines by

50 intranasal (IN) or intramuscular (IM) routes, SC-Ad produced significantly stronger

51 antibody responses as compared to RD-Ad against the spike protein that rose over 14

52 weeks after one immunization. Single IN or IM immunizations generated significant

53 antibody responses in serum and in bronchoalveolar lavages (BALs). IN priming, but not

54 IM priming, generated HLA-restricted CD8 T cell responses in BALs. SC-Ad-Spike

55 generated antibodies that retain binding to spike receptor binding domains (RBDs) with

56 mutations from new viral variants. These data suggest empowering the genomes of gene-

57 based vaccines with the ability to amplify antigen genes can increase potency. This may

58 be particularly advantageous when applying mucosal vaccines to combat mucosal

59 pathogens like SARS-CoV-2.

60 


\section{One Sentence Summary}

62 Arming adenovirus vaccines with the ability to replicate vaccine antigen genes may

63 increase potency for systemic, or more importantly, mucosal immunization against

64 mucosal pathogens.

67 In December 2019, a cluster of pneumonia cases were identified in Wuhan, China, which

68 were later found to be caused by a novel coronavirus: severe acute respiratory syndrome

69 coronavirus-2 (SARS-CoV-2) (Li \& al., 2020) (Gralinski \& Menachery, 2020). As of April

702021 , there have been over $130,000,000$ cases and nearly $3,000,000$ deaths world-wide

71 (Johns Hopkins University Coronavirus Resource Center).

72 Nearly every vaccine technology has been deployed to combat this pandemic (reviewed

73 in (1)). mRNA vaccines advanced through the development and regulatory processes

74 most quickly and have been given emergency authorization from the FDA and other

75 international regulators. Replication-defective adenovirus (RD-Ad) gene-based vaccines

76 have also been advanced by several countries and companies, including chimpanzee Ad,

77 human Ad serotype 5 (Ad5), human Ad serotype 26 (Ad26), and others. Each of these

78 vaccines has their strengths and weaknesses, and most will not be revealed until human

79 studies are completed.

80 While many of the advanced vaccines have great promise, they perhaps miss out on two 81 opportunities to combat SARS-CoV-2 and other mucosal pathogens. First, most COVID- 
8219 vaccines are administered intramuscularly (IM) and not at the site of SARS-CoV-2

83 entry into the body. Second, most COVID-19 vaccines do not harness the power of

84 transgene replication to amplify antigen production and immune responses.

85 Most Ad vaccines are RD-Ads (reviewed in $(2,3)$ ). For example, the Johnson \& Johnson

86 human Ad26 vaccine (4), the ChAdOx1 vaccine from Oxford/AstraZeneca (5), the

87 Russian Sputnik V Ad26 and Ad5 vaccines (6), and most others are RD-Ad vaccines.

88 Converting a wild replication-competent Ad to an RD-Ad is achieved by deleting the

89 adenovirus' pivotal master regulator gene, E1, to prevent them from causing Ad

90 infections. An RD-Ad can efficiently deliver vaccine genes into cells to transcribe and

91 translate vaccine antigens. However, after gene delivery, the DNA genome of an RD-Ad

92 is not replicated (reviewed in (2, 3)). Therefore, one incoming RD-Ad vaccine antigen

93 gene remains one gene. This gene can be very efficiently expressed, but it is not

94 amplified.

95 By contrast, an E1-intact replication-competent adenovirus (RC-Ad) vector will infect a

96 human cell and replicate an antigen gene DNA up to 10,000-fold in each infected cell (7-

97 18). While RC-Ad vaccines are documented to be more potent than benchmark RD-Ad

98 vectors, RC-Ads can cause actual adenovirus infections in vaccinees (19).

99 We developed single-cycle Ad (SC-Ad) vectors to take advantage of DNA replication 100 while disabling the production of infectious progeny viruses (20-23). SC-Ads retain E1

101 genes and replicate their DNA just as well as RC-Ads, but are deleted for the gene for 102 Ad's pllla capsid cement protein, so that they produce empty defective particles (20). SC103 Ads appear able to generate more robust and persistent immune responses than RD-Ads 
$104(21,24)$ and have shown promise as vaccines against influenza (24), Ebola virus, HIV-1

105 (25-27), and against Clostridium difficile after single immunization (22, 28).

106 In this work, we generated RD-Ad and SC-Ad vectors expressing the wild-type original

107 SARS-CoV-2 spike protein. Here, we compare the ability of RD-Ad and SC-Ad to produce

108 the spike protein and generate immune responses in small animals. We also compare

109 the ability of mucosal intranasal (IN) immunization relative to systemic intramuscular (IM)

110 immunization to generate immune responses in systemic and mucosal compartments.

\section{Materials and Methods}

112 Single-cycle Adenovirus Expressing Wild-type SARS-CoV-2 spike. A codon-

113 optimized cDNA encoding the original wild-type spike protein from severe acute

114 respiratory syndrome coronavirus 2 isolate 2019-nCoV_HKU-SZ-002a_2020, accession

115 number MN938384.1 was synthesized by Genewiz. This full-length sequence was

116 inserted into the shuttle plasmid pAd6-NdePfl-CMV-MCS-3X-LZL. This sequence was

117 recombined into $p A d 6-\Delta E 1-\Delta E 3$ and $p A d 6-\Delta$ Illa- $\Delta E 3$ by red recombination as in (20-22)

118 to generate RD-Ad6-spike and SC-Ad-Spike, respectively. These viruses were cut with

119 AsiSI to liberate their viral genomes, and these were transfected into 293-IIIA cells to

120 rescue the viruses. The viruses were purified from 10 Plate CellStacks (Corning) on two

$121 \mathrm{CsCl}$ gradients and used as virus particles (vp) based on OD260 measurements (20-22).

122 Western Blotting. Human A549 lung cells were infected with RD- or SC-Ad spike at the

123 indicated multiplicities of infection (MOI) and harvested 24 hours later. 5X sodium dodecyl

124 sulfate with $5 \mathrm{mM}$ dithiothreitol was added to cell lysate and heat-inactivated at $95^{\circ} \mathrm{C}$ for 5 
125 minutes. Cell lysate was run by western blot using PowerPac ${ }^{\mathrm{TM}} \mathrm{HC}$ (Bio-Rad) at 110 volts

126 for 70 minutes. Gel was incubated in $1 \mathrm{X}$ transfer buffer while the membrane was

127 prepared. Membrane was prepared by soaking 15 seconds in methanol, shaking 2

128 minutes in $\mathrm{ddH}_{2} \mathrm{O}$ on orbital shaker, and shaking 5 minutes in $1 \mathrm{X}$ transfer buffer. Gel was

129 transferred to membrane via TransBlot ${ }^{\circledR}$ SD Semi-Dry Transfer Cell (Bio-Rad) at 15 volts

130 for 15 minutes. Membrane was washed with 1X TBST on orbital shaker for 5 minutes.

131 Membrane was incubated on orbital shaker in blocking buffer (5\% milk powder in TBST)

132 for 2 hours at room temperature. Membrane was washed with 1X TBST 3 times for 15

133 seconds each, then 3 times for 5 minutes each. Membrane was incubated in primary

134 antibody, SARS-CoV-2 spike antibody [1A9] (GeneTex), diluted in blocking buffer at a

135 1:1000 dilution for 1 hour. Membrane was washed with 1X TBST 3 times for 15 seconds

136 each, then 3 times for 5 minutes each. Membrane was incubated in secondary antibody,

137 GOXMO HRP HIGH XADS (Invitrogen), diluted in blocking buffer at a 1:10,000 dilution

138 for 1 hour. Membrane was washed with 1X TBST 3 times for 15 seconds each, then 3

139 times for 5 minutes each. Membrane was coated with $750 \mu \mathrm{L}$ SuperSignal ${ }^{\mathrm{TM}}$ West

140 Maximum Sensitivity Substrate (Thermo Scientific) and imaged on the

141 ChemiDoc ${ }^{\mathrm{TM}}$ Imaging System (Bio-Rad).

142 Animals. BALB/c mice were purchased from Charles River Laboratories. Syrian

143 hamsters were purchased from Envigo. All animal handling and experiments were carried

144 out according to the provisions of the Animal Welfare Act, PHS Animal Welfare Policy,

145 the principles of the NIH Guide for the Care and Use of Laboratory Animals, and the

146 policies and procedures of the Mayo Clinic. This study was conducted in Mayo Clinic's

147 AAALAC (Association for the Assessment and Accreditation of Laboratory Animal Care)- 
148 accredited facilities and were approved by the Institutional Animal Care and Use

149 Committee (IACUC). Mice and hamsters were housed in the Mayo Clinic Animal Facility.

150 Immunizations. Mice and hamsters were anesthetized with isoflurane prior to

151 immunizations by the indicated routes: intramuscular (IM), intranasal (IN), sublingual

152 (Sub). For intramuscular immunization, $50 \mu \mathrm{L}$ of a solution of virus diluted in PBS was

153 injected into each flank for a total volume of $100 \mu \mathrm{L}$ per animal. Intranasal immunization

154 was performed by pipetting $40 \mu \mathrm{L}$ of a solution of virus diluted in PBS dropwise into the

155 nostrils of each animal. Each animal received a total volume of $40 \mu \mathrm{L}$, alternating pipetting

156 between nostrils.

157 Bronchoalveolar Lavage (BAL). BALs were performed as described in (29). Mice were

158 euthanized via $\mathrm{CO}_{2}$ gas, then sterilized with $70 \%$ ethanol. Scissors were used to open

159 the chest cavity up to the chin and to expose the trachea. A razor was used to puncture

160 the trachea, and $1 \mathrm{~mL}$ PBS was pipetted into and out of the lungs. This was repeated 2

161 additional times, giving a total volume of $3 \mathrm{~mL}$. Cells were then pelleted out of the

162 bronchoalveolar lavage fluid by centrifugation. The cells were used to run flow cytometry,

163 and the supernatant fluid was used to run ELISA.

164 Lung Tissue Single Cell Suspension. Lung cells were isolated as described in (29).

165 Briefly, lungs were extracted and processed with a gentleMACS dissociator (Miltenyi

166 Biotec) and placed in gentleMACS C tubes containing 2.5mL RPMI, $40.4 \mu \mathrm{l}$ of $14 \mathrm{U} / \mathrm{mL}$

167 concentration Roche Liberase TM, and $62.5 \mu \mathrm{l}$ DNase I at $1 \mathrm{mg} / \mathrm{mL}$ concentration.

168 Program Lung_01 was performed on the gentleMACS dissociator, followed by a one-hour

169 incubation at $37^{\circ} \mathrm{C} .2 .5 \mathrm{~mL}$ RPMI with $10 \%$ fetal bovine serum was added before running 
170 program Lung_02. All tubes were centrifuged for 5 minutes at $250 \mathrm{xg}$, and the contents

171 were transferred to a $50 \mathrm{~mL}$ conical tube via a $70 \mu \mathrm{m}$ mesh. $2.5 \mathrm{~mL}$ RPMI with $10 \%$ fetal

172 bovine serum was added to the gentleMACS tubes and poured over the mesh to wash.

$17350 \mathrm{~mL}$ conical tubes were centrifuged for 10 minutes at $250 \mathrm{xg}$, and the supernatant was

174 aspirated and discarded. Cell pellets were resuspended in $2 \mathrm{~mL}$ ammonium-chloride-

175 potassium lysis buffer and centrifuged for 5 minutes at $350 \mathrm{xg}$. Supernatants from this

176 reaction were discarded and the cell pellet was washed by resuspending in $2 \mathrm{~mL}$ PBS

177 and was centrifuged for 5 minutes at $350 \mathrm{xg}$. Supernatants were extracted and discarded.

178 The cell pellet was resuspended in desired volume RPMI and analyzed by flow cytometry.

179 Sample Collections. At indicated time points, the animals were anesthetized with

180 isoflurane and serum was collected by cheek bleed in mice or from jugular veins in

181 hamsters. In addition, for bronchoalveolar lavage, the mice were euthanized via $\mathrm{CO}_{2}$ and

182 bronchoalveolar lavage was performed according to the procedure described.

183 Antibody ELISAs. Binding $\lg G$ and $\lg A$ antibody responses in mouse serum, hamster

184 serum, and bronchoalveolar lavage fluid were measured by ELISA against spike S1

185 protein and SARS-CoV-2 receptor binding domain variants. Flat-bottom plates

186 (ThermoFisher) were coated with $10 \mathrm{ng} /$ well of spike S1 antigen in $100 \mu \mathrm{l}$ PBS or 100

187 ng/well SARS-CoV-2 receptor binding domain variant antigen in $100 \mu$ PBS, including a

188 triplicate of negative control wells, which received no protein antigen. The protein antigen

189 used for most SARS-CoV-2 ELISAs was recombinant SARS-CoV-2 (2019-nCoV) spike

190 S1-Fc from Sino Biological. The protein antigen used for the SARS-CoV-2 variants

191 included S1 proteins and receptor binding domain (RBD) Recombinant Proteins, also 
192 from Sino Biological. These included the following His6-tagged proteins expressed from

193293 human cells: Wild-type; K417N; N429K; Y453F; S477N; E484K; N501Y; and K417N,

194 E484K, N501Y, triple mutant corresponding to the South African variant, B.1.351. spike

195 S1s with the single D614G and K417N, E484K, N501Y were also tested.

196 Plates were left overnight at $4^{\circ} \mathrm{C}$. Plates were washed with $200 \mu \mathrm{l}$ 1X PBS 2 times,

197 followed by adding $200 \mu \mathrm{l}$ per well of blocking buffer, consisting of $5 \%$ milk powder in

198 TBST, for 2 hours at room temperature. Plates were washed with $200 \mu \mathrm{l}$ 1X PBS 2 times.

199 All samples were run in triplicate, including a triplicate of positive and negative control

200 wells in each plate. Samples were serially diluted in blocking buffer and were transferred

201 to the assay plate and incubated for 3 hours at room temperature. For the positive control

202 wells, SARS-CoV-2 spike antibody [1A9] (GeneTex) was used as the primary antibody.

203 Plates were washed with $200 \mu \mathrm{l}$ 1X PBS 4 times, followed by addition of the secondary

204 antibody. For hamster samples, the secondary antibodies used were: Peroxidase

205 Conjugated Affinity Purified Anti-Golden Syrian Hamster IgG (H\&L) Goat (Rockland Inc.),

206 and Rabbit Anti-Hamster IgA (Brookwood Biomedical). For mouse samples, the

207 secondary antibodies used were: GOXMO HRP HIGH XADS (Invitrogen), and HRP-Goat

208 Anti-Mouse IgA (Invitrogen). The secondary antibody for the positive controls was Purified

209 Recomb ${ }^{\mathrm{TM}}$ Protein A/G Peroxidase Conjugated (Invitrogen). Plates were left to incubate

210 with the primary antibody for 2 hours at room temperature. Plates were washed with 200

$211 \mu \mathrm{l}$ 1X PBS 4 times. $50 \mu \mathrm{l}$ 1-Step ${ }^{\mathrm{TM}}$ Ultra TMB-ELISA was added to each well and left at

212 room temperature for 30 minutes, then $50 \mu \mathrm{l} 2 \mathrm{M}$ sulfuric acid was added to each well.

213 Plates were read at 450nm in a Synergy H1 microplate reader (BioTek). All statistical

214 analyses were done by one-way ANOVA. 
215 Neutralization Assays. Pseudo-neutralization assays were performed on hamster

216 serum using the $\mathrm{cPass}^{\mathrm{TM}}$ Neutralization Antibody Detection kit (GenScript).

217 ELISPOT Assay for Detecting Antigen-specific IFN-y producing Cells. Freshly-

218 isolated splenocytes were stimulated with spike S1 or S2 subunit protein $(1 \mu \mathrm{g} / \mathrm{mL})$ to

219 determine the numbers of IFN-Y-producing cells by the Enzyme Linked Immuno Spot

220 (ELISPOT) assay using the methodology reported previously (30). Briefly, splenocytes

221 were plated at $2.5 \times 10^{5}$ cells per well in triplicate in 96-well plates. Cells were incubated

222 at $37^{\circ} \mathrm{C}$ with medium alone, human papilloma virus E7 peptide (negative control), SARS-

223 CoV-2 spike protein $\mathrm{S} 1$ subunit $(1 \mu \mathrm{g} / \mathrm{ml})$, SARS-CoV-2 spike protein $\mathrm{S} 2$ subunit $(1$

$224 \mu \mathrm{g} / \mathrm{ml}$ ), tetanus toxoid (TT, negative control, $100 \mathrm{ng} / \mathrm{ml})$ ), or concanavalin A (Con A),

225 positive control, $10 \mathrm{ng} / \mathrm{ml}$. After $24 \mathrm{~h}$, cells were transferred to nitrocellulose plates, coated

226 with anti-IFN-Y antibody, and incubated for 24 more hours. Plates were then washed and

227 incubated with biotinylated anti-IFN-y antibody, streptavidin-alkaline phosphatase, and

228 colorimetric substrate, with washes between each step. After drying overnight, the plates

229 were read on an AID ELIspot reader (San Diego, CA). Antigen-specific T cells were

230 defined as the average number of spots elicited by the antigen of interest minus the

231 average number of spots elicited when cells were incubated with culture medium alone,

232 without the addition of any peptides.

233 Flow Cytometry. Bronchoalveolar lavage samples were centrifuged at 1500rpm for 5

234 minutes, and the supernatant BAL fluid was removed. The cell pellet was resuspended

235 in $200 \mu \mathrm{l} \mathrm{T-Cell} \mathrm{Media} \mathrm{(IMDM} \mathrm{with} \mathrm{10 \%} \mathrm{FBS,} \mathrm{Pen/Strep,} \mathrm{and} \mathrm{2-ME),} \mathrm{and} \mathrm{was} \mathrm{then} \mathrm{added}$

236 to a $96-$-well plate. $2 \mu$ l of stimulating $\operatorname{mix}(500 \mu \mathrm{g} / \mathrm{mL}$ ionomycin, $50 \mu \mathrm{g} / \mathrm{mL}$ PMA, and 445 
$237 \mu \mathrm{l}$ T-Cell Media) was added to each well to be stimulated, and was incubated overnight 238 at $37^{\circ} \mathrm{C} .100 \mu \mathrm{l}$ of a GolgiPlug Mix $(1 \mu \mathrm{l} \mathrm{GolgiPlug} / 1 \mathrm{~mL}$ T-Cell Media) was added to each

239 well and thoroughly mixed by pipetting before incubating for $4-6$ hours at $37^{\circ} \mathrm{C}$. Cells 240 were centrifuged at 1500rpm for 5 minutes and supernatant was removed. Cell surface 241 antibodies were added in $50 \mu \mathrm{l}$ total volume in FACS Buffer, then incubated 30 minutes

242 on ice. Plates were washed twice with FACS buffer, resuspending cells in FACS Buffer 243 and centrifuging for 5 minutes at 1500rpm to remove supernatant. The cells were then 244 pelleted by centrifugation at 1500 rpm for 5 minutes. Cell pellet was resuspended in 100 $245 \mu \mathrm{l}$ of Fix/Perm Solution for 20 minutes at $4^{\circ} \mathrm{C}$ before being washed twice with $1 \mathrm{X}$ BD 246 Perm/Wash Buffer, then centrifuging at 1500rpm for 5 minutes to pellet. Intracellular 247 cytokine antibodies were diluted in $50 \mu \mathrm{l}$ 1X BD Perm/Wash Buffer and added to each 248 well. Plate was then incubated 30 minutes on ice. Plates were washed twice with $1 X$ BD 249 Perm/Wash Buffer, resuspending cells in 1X BD Perm/Wash Buffer and centrifuging for 2505 minutes at $1500 \mathrm{rpm}$ to remove supernatant. Cells were resuspended in $500 \mu \mathrm{l} 1 \%$ PFA 251 and left at $4^{\circ} \mathrm{C}$ overnight before flow cytometry analysis.

252 Statistical Analysis. Prism 9 Graphical software was used for all statistical analyses.

253 RESULTS

254 Replication-defective and Single-cycle Adenoviruses Expressing SARS-CoV-2

255 Spike Protein. A codon-optimized cDNA encoding the original wild-type spike protein 256 from the 2019-nCoV HKU-SZ-002a 2020 isolate was inserted into adenovirus vectors. 257 This cDNA uses all native spike sequences and secretory leader and does not bear 
258 modifications such as proline mutations to alter spike structure $(4,5,31)$. This cDNA was

259 inserted into a cytomegalovirus (CMV) expression cassette and was used to generate

260 human adenovirus serotype 6 (HAdV-C6, Ad6) vectors RD-Ad6-spike and SC-Ad6-spike,

261 respectively (Fig. 1A). These vectors were tested for spike protein expression by infection

262 of human A549 lung cells at varied multiplicities of infection (MOI) (Fig. 1B). Western blot

263 on cells harvested 24 hours after infection demonstrated that both vectors produced spike

264 protein; however, RD-Ad-Spike only generated detectable protein with $10^{4}$ virus particles

265 (vp) per cell, but not with 100 vp/cell. In contrast, SC-Ad-Spike produced protein with 100

266 or more vp/cell with higher expression than RD-Ad at each dose.

267 Comparison of Antibody Responses by RD-Ad-Spike and SC-Ad-Spike in

268 Adenovirus-permissive Syrian Hamsters. Human Ad6 replicates its genome up to

269100,000 -fold in human cells (32, 33). SC-Ad replicates DNA identically to RC-Ad (33).

270 Unfortunately, mice do not support the full life cycle or replication of human adenoviruses

271 (34). Therefore, the administration of SC-Ad to mice may underrepresent the effect of

272 transgene amplification that would be observed in humans and model organisms that are

273 permissive to human adenovirus infection. In contrast to mice, Syrian hamsters are

274 partially permissive for human adenoviruses (34) and their cells allow 350-fold replication

275 of Ad6 DNA after infection (24). Immunization by RD-Ad and SC-Ad-Spike were therefore

276 compared in Ad6-permissive Syrian hamsters to allow at least partial DNA replication to

277 occur.

$27810^{9} \mathrm{vp}$ of RD-Ad-Spike and SC-Ad-Spike were used to immunize male Syrian hamsters

279 by IN and IM routes. These were compared to negative control RD- and SC-Ad 
expressing GFP-Luciferase (GL). Animals were immunized a single time and sera were

281 collected at varied times thereafter (Fig. 2). Under these conditions, SC-Ad-Spike 282 generated significantly higher spike antibody levels than RD-Ad-GL or SC-Ad-GL 283 expressing GFP-Luciferase or when compared to RD-Ad-Spike at a fixed dilution $284(1 / 1,000)$ of sera. SC-Ad-Spike delivered by the intramuscular route generated higher IgG 285 at all time points through 6 months after single immunization $(p<0.0001$ by ANOVA) 286 (Figs. 2 and 3 C and D). SC-Ad-Spike by the intranasal route generated significantly 287 higher lgG in sera at 6 weeks and 14 weeks, but not at 2 weeks and 6 months after single 288 immunization $(p<0.0001$ and $p<0.001$ at 6 and 14 weeks). Serial dilution of these sera 289 samples revealed reciprocal endpoint spike binding titers of 100 for RD-Ad-Spike by both 290 routes (Fig. 3A). In contrast, SC-Ad-Spike by IN route had reciprocal binding titers of $2911,000(p<0.05)$. SC-Ad-Spike by the IM route had reciprocal titers of 1,000 or greater ( $p$ $292<0.0001)$. This experiment was repeated in female Syrian hamsters with similar results 293 (Supplemental Figs. 2 and 3).

294 Varied dilutions of 6-week sera were assayed for SARS-CoV-2 neutralization antibodies 295 with the CPass $^{\mathrm{TM}}$ Neutralization Antibody Detection kit that assays antibodies that block 296 binding of spike receptor binding domain (RBD) to ACE2. Under these conditions, RD-Ad

297 vaccinated hamsters failed to generate significant spike RBD inhibition at any dilution. In 298 contrast, animals immunized with SC-Ad-Spike by the IN and IM route had significantly 299 higher inhibition at all dilutions than RD-Ads within 6 weeks of single immunization (Fig. 300 3B). 
301 Antibody Binding to Spike Variants. SARS-CoV-2 has undergone rampant viral

302 evolution as it has infected millions of humans. The emergence of SARS-CoV-2 variant

303 B.1.1.7 in the UK, B.1.351 in South Africa, P.1 in Brazil, and a rash of other new variants

304 raise significant concerns about the ability of vaccines to protect against them (35-37).

305 These mutations are particularly concerning when they affect antibodies that bind to the

306 ACE2 receptor binding domain, RBD, of spike. The SARS-CoV-2 variant B.1.1.7 contains

307 H69del, V70del, Y144del, N501Y, A570D, D614G, and P681H mutations. The B.1.351

308 has K417N, E484K, N501Y, and D614G mutations. The P.1 variant bears K417T, E484K,

309 and N501Y mutations (35-37). Mutations in the RBD domain are of most concern

310 considering that they can impact the ability of neutralizing antibodies to block binding of

311 the spike protein to ACE2.

312 Given concerns about these variants, week 14 sera from hamsters immunized IM with

313 the negative control vaccine SC-Ad-GL and SC-Ad-Spike (Fig. 2 and 3) were compared

314 for their ability to bind spike RBD (amino acids 319 to 541) and S1 variants (amino acids

31516 to 685$)($ Fig. 4 and Supplemental Fig. 3). The RBD from the original SARS virus was

316 also included as a reference. ELISAs performed at 1/1,000 dilutions demonstrated

317 significant binding by samples from SC-Ad-Spike immunized animals to all the variant

318 RBDs and S1 proteins when compared to SC-Ad-GL samples ( $p<0.0001$ by one-way

319 ANOVA). SC-Ad-Spike bound the RBD from the original SARS-1 virus, but this did not

320 reach significance at $1 / 1,000$. When the samples were tested at $1 / 10,000$ dilutions binding

321 remained significant with $p$ values remaining less than 0.0001 for all samples except the

322 RBD with combined K417N, E484K, N501Y, which fell to a $p$ value of less than 0.01 .

323 ELISA binding to the single E484K RBD was higher at this dilution than to other RBDs, 
324 suggesting some difference in structure or an artifact. When further $1 / 20,000$ dilutions were tested, binding to all variants was still significantly different between SC-Ad-Spike and SC-Ad-GL samples ( $p<0.05$ to 0.0001 ), except for K417N, E484K, N501Y RBD,

327 which was no longer significantly different. While binding to the K417N, E484K, N501Y

328 RBD was lost, binding to the larger S1 protein with K417N, E484K, N501Y, and D614G

329 mutations remained significant $(p<0.01)$. This was not unexpected, since the larger spike

330 S1 protein has many more epitopes for polyclonal antibody binding.

331 Comparison of the Routes of Immunization by SC-Ad-Spike in Mice. Mice were

332 utilized to evaluate the effects of the route of immunization of SC-Ad-Spike, since few

333 immunological reagents exist to evaluate these responses in hamsters. BALB/c mice

334 were immunized by IN and IM routes with PBS, $10^{10}$ vp of SC-Ad expressing Zika E 335 protein, or $10^{10} \mathrm{vp}$ of SC-Ad-Spike, and antibody responses were evaluated. This 10-fold

336 higher dose was used to compensate for the lack of SC-Ad-Spike DNA replication in the

337 mouse model. Under these conditions, mice immunized with SC-Ad-Spike generated 338 robust IgG antibody responses within 2 weeks of immunization $(p<0.0001$ by one-way 339 ANOVA by both routes, Fig. 5).

340 Effects of the Routes of Immunization on Mucosal Antibody Responses in the

341 Lungs. Five animals from selected groups in Fig. 5 were sacrificed 8 weeks after single

342 immunization and bronchoalveolar lavages (BALs) were performed to collect mucosal

343 antibodies and immune cells from the lungs. The $3 \mathrm{~mL}$ BAL washes were diluted 1/500

344 and were used to detect anti-spike IgG and IgA antibodies by ELISA. By 8 weeks after 345 single immunization, the mice had significant levels of $\lg G$ antibodies in their BALs $(p<$ 
3460.01 and 0.001 , Fig. 6A). Notably, significant anti-spike IgA antibodies were only

347 observed in IN-immunized mice $(p<0.01)$. When BAL samples were tested for RBD

348 neutralizing activity, both the IN and IM-immunized mice had significant activities $(p<$

3490.01 and 0.05 , respectively, Fig. 6B).

350 Effects of the Routes of Immunization on Mucosal T Cell Responses in the Lungs.

351 BAL samples were also examined for the presence of $T$ cells in the lung. The small

352 number of cells obtained and an absence of known spike T cell epitopes for BALB/c mice

353 precluded testing for spike-specific responses; however, when flow cytometry was

354 performed, IFN- $\gamma$ and IL-4-expressing CD4 and CD8 T cells were detected in BAL

355 samples (Fig. 7). These analyses revealed no significant increases in CD4 or CD8 T cells

356 in BAL samples after IM immunization. In contrast, there were significant increases in

$357 \mathrm{CD}^{+} \mathrm{IFN}-\gamma^{+}, \mathrm{CD} 4^{+} \mathrm{IFN}-\gamma^{+}$, and $\mathrm{CD} 4^{+} \mathrm{IL}-4^{+} \mathrm{T}$ cells in the BALs of animals immunized

358 intranasally with either SC-Ad-Zika E or SC-Ad-Spike.

359 Effects of the Routes of Immunization on Systemic T Cell Responses. Splenocytes

360 from the animals in Fig. 7 were assayed for IFN- $\gamma$, IL-17, and IL-4-expression by ELISPOT

361 after stimulation with spike S1 whole protein subunit (Supplemental Fig. 4). These data

362 demonstrated higher splenocyte IFN- $\gamma$, IL-17, and IL-4 responses in the BALB/c mice after

363 IN immunization than after IM immunization.

364 DISCUSSION

365 The purpose of this study was to compare RD- and SC-Ad vaccines expressing the 366 SARS-CoV-2 spike protein and to evaluate whether mucosal immunization may have 
367 utility when considering vaccines against a mucosal pathogen like SARS-CoV-2. These

368 data suggest that vaccines that retain the ability to replicate their DNA can drive more 369 potent and long-lasting immune responses than non-replicating vaccines. These data

370 also suggest that there may be advantages to delivering vaccines at mucosal sites by

371 single immunization or as a prime followed by later boost.

372 Consistent with previous comparisons, SC-Ad expressed higher levels of antigen than

373 matched RD-Ad vector. This higher expression by SC-Ad-Spike translated into higher

374 serum antibody responses than RD-Ad-Spike in adenovirus-permissive Syrian hamsters

375 after single immunization by either the IM or IN route. The levels of antibodies in sera

376 were higher in animals immunized by the intramuscular route than the intranasal route.

377 In all the animal models, antibody titers were higher in ELISA assays than in varied 378 neutralization assays, as expected. This may reflect, in part, the use of the wild-type spike 379 protein sequence rather than modified spikes locked in the "up" position (4). Use of such 380 a modified spike would likely increase neutralization by SC-Ad.

381 SC-Ad-Spike generated antibodies from these hamsters were able to cross-react in

382 ELISA assays against several single point mutant RBD variants, including those observed

383 in the U.K. B.1.1.7 strain and the South African B.1.351 strain. These antibodies were 384 also able to bind K417N, E484K, N501Y RBD at 1/1,000 and 1/10,000 dilutions in ELISA, 385 but were insignificant at $1 / 20,000$ dilutions. This was not surprising given that the 386 presence of three separate mutations have been shown to affect the ability of Pfizer, 387 Moderna, and other vaccines to recognize these new variants. 
388 The single-cycle replication "engine" can be applied to any adenovirus serotype. This

389 increased potency could be utilized in two ways. In one, SC-Ad is delivered at the same

390 virus particle doses as current RD-Ad COVID-19 vaccines to garner stronger immune

391 responses. In the second, SC-Ad is used at a lower dose, perhaps 10 to 100 -fold lower,

392 to deliver equal potency to RD-Ad vaccines, but allowing 10 to 100 times more vaccine

393 doses from the same size of a GMP vaccine production run. This could be pivotal for

394 expanding access to vaccines for this pandemic or the next to vaccinate people in rich

395 and poorer countries.

396 Species C human Ad6 was used to test proof of concept since it is equal to or is more

397 robust than species C Ad5 as a vaccine or as an oncolytic (32, 38-42). Species C Ad5

398 and Ad6 also appear to be more robust as gene-based vaccines than lower seroprevalent

399 viruses like species D Ad26 and species E ChAdOx1 (38, 39, 43, 44).

400 Another interesting aspect of this work was examining if there is utility in applying these

401 gene-based vaccines at mucosal surfaces. Hamsters have few immune reagents, so this

402 was examined in more detail in mouse models. In mice, we show that intranasal

403 immunization generated equal IgG antibodies in the lungs of mice, but higher IgA and

404 CD4 and CD8 T cells in BAL samples. Intramuscular immunization was able to generate

405 IgG antibodies in BAL fluid. However, the IM route reduce markedly low IgA antibodies

406 than the IN route. Likewise, IM immunization failed to traffic CD4 or CD8 T cells to the

407 lumen of the lung in contrast to IN mucosal immunization. These data suggest that IN

408 mucosal routes of immunization may do a better job at placing effector antibody and T

409 cells at the sites of earliest exposure to SARS-CoV-2. 
410 These observations are consistent with our previous observations testing IN and IM

411 prime-boosts with SC-Ad expressing HIV envelope in rhesus macaques (26). Animals

412 immunized with SC-Ad by only the IM route had lower HIV-1 antibody-dependent cellular

413 cytotoxicity (ADCC) antibody activity and lower levels of peripheral $\mathrm{T}$ follicular helper

414 ( $p$ Tfh) cells in their lymph nodes. Conversely, animals immunized with SC-Ad by the IN

415 route had higher ADCC, higher Tfh cell counts in lymph nodes, and lower SHIV viral loads

416 in their gastrointestinal tracts after rectal SHIV challenge (26). These data suggest that

417 there may be benefits in priming the immune system at mucosal sites when immunizing

418 against pathogens that also enter at these sites.

419 Mucosal immunization may also have utility to impact vaccine safety. There are concerns

420 with observations of thrombotic thrombocytopenia in a small number of people who have

421 received the Ad26 and ChAdOx1 COVID-19 $(45,46)$. These vaccines were delivered by

422 the intramuscular route. Adenoviruses do not naturally infect the muscle. Ads naturally

423 infect humans at some mucosal site (reviewed in (47)). Injection of anything into the

424 muscle can breach blood vessels and allow leak into the bloodstream. For an

425 intramuscular Ad vaccine, this can cause adenovirus to be absorbed by liver Kupffer cells,

426 liver sinusoidal endothelial cells, and to productively infect liver hepatocytes, spleen, or

427 lungs. It is therefore possible that injecting Ads into the muscle by this unnatural route

428 may elevate the risk of side effects. It is possible that delivering adenovirus vaccines by

429 intranasal vaccination may avoid some of these new risks. That having been said, it 430 should be noted that intranasal immunization has its own possible side effects including 431 retrograde transport into the olfactory bulb and Bell's palsy. 
432 Another consideration is the use of adenoviruses that are low seroprevalent in humans.

433 The primary advantage of Ad26 and ChAdOx1 is that few people have been exposed

434 them naturally and so most people do not have neutralizing antibodies against these

435 vaccines. While that is true, it also means that there is less experience with how these

436 viruses behave in humans and what side effects may be observed.

437 In contrast, 27 to $100 \%$ of humans are immune to Ad5 (43). Ad6 is lower seroprevalent

438 than Ad5, with 4 to $22 \%$ of humans having already been exposed to $\operatorname{Ad} 6(48,49)$. In both

439 cases, these humans have experienced these species C Ads after mucosal exposure

440 without obvious connections to side effects associated with COVID-19 vaccines. One

441 might say that both Ad5 and Ad6 have been field tested as mucosal vaccines in as many

442 as a billion humans. Conversely, no humans have been naturally exposed to Ad5, Ad6,

443 Ad26, or ChAdOx1 by intramuscular exposure.

444 While these common human adenoviruses may have some ironic safety value, it is still

445 possible that arming any adenovirus or any gene-based vaccine with the SARS-CoV-2

446 spike protein may by itself play a role in the observed thrombotic side effects by

447 intramuscular or mucosal routes of vaccination.

448 These concepts need to be explored further. Regardless, this study suggests that 449 mucosal immunization may have value when combating SARS-CoV-2 and other mucosal 450 pathogens. This work also suggests that giving adenovirus vaccines the ability to replicate 451 via single-cycle modifications may have value in increasing per virus potency or by 452 allowing more doses to be produced by using fewer virions per person. 
453 Acknowledgements. This work was funded by grants from Fastgrants.org/Mercatus and

454 from the Harrington Foundation COVID-19 Scholar Program to M.A.B. This project was

455 supported by the Walter \& Lucille Rubin Fund in Infectious Diseases Honoring Michael

456 Camilleri, M.D. at Mayo Clinic. This project would not have been possible without 457 generous support from Mayo Benefactors and the Mayo Clinic COVID-19 Task Force. 


\section{REFERENCES.}

461 1. B. M. Prubeta, Current State of the First COVID-19 Vaccines. Vaccines 9, (2021).

462 2. M. O. Lasaro, H. C. Ertl, New insights on adenovirus as vaccine vectors. Mol Ther 463 $17,1333-1339$ (2009).

464 3. M. Barry, Single-cycle adenovirus vectors in the current vaccine landscape. Expert Rev Vaccines 17, 163-173 (2018).

4664 N. B. Mercado, R. Zahn, F. Wegmann, C. Loos, A. Chandrashekar, J. Yu, J. Liu, L. Peter, K. McMahan, L. H. Tostanoski, X. He, D. R. Martinez, L. Rutten, R. Bos, D. van Manen, J. Vellinga, J. Custers, J. P. Langedijk, T. Kwaks, M. J. G. Bakkers, Feldman, B. M. Hauser, T. M. Caradonna, E. A. Bondzie, G. Dagotto, M. S. Gebre, R. Brown, A. Cook, S. Zouantchangadou, E. Teow, H. Andersen, M. G. Lewis, Y.

479 5. N. van Doremalen, T. Lambe, A. Spencer, S. Belij-Rammerstorfer, J. N. 480 Purushotham, J. R. Port, V. A. Avanzato, T. Bushmaker, A. Flaxman, M. 481 Ulaszewska, F. Feldmann, E. R. Allen, H. Sharpe, J. Schulz, M. Holbrook, A. 482 Cai, B. Chen, A. G. Schmidt, R. K. Reeves, R. S. Baric, D. A. Lauffenburger, G. Alter, P. Stoffels, M. Mammen, J. Van Hoof, H. Schuitemaker, D. H. Barouch, Single-shot Ad26 vaccine protects against SARS-CoV-2 in rhesus macaques. Nature 586, 583-588 (2020). Okumura, K. Meade-White, L. Perez-Perez, N. J. Edwards, D. Wright, C. Bissett, 

de Wit, S. C. Gilbert, V. J. Munster, ChAdOx1 nCoV-19 vaccine prevents SARSCoV-2 pneumonia in rhesus macaques. Nature, (2020).

487 6. D. Y. Logunov, I. V. Dolzhikova, O. V. Zubkova, A. I. Tukhvatullin, D. V. Shcheblyakov, A. S. Dzharullaeva, D. M. Grousova, A. S. Erokhova, A. V. Kovyrshina, A. G. Botikov, F. M. Izhaeva, O. Popova, T. A. Ozharovskaya, I. B. Esmagambetov, I. A. Favorskaya, D. I. Zrelkin, D. V. Voronina, D. N. Shcherbinin, A. S. Semikhin, Y. V. Simakova, E. A. Tokarskaya, N. L. Lubenets, D. A. Egorova, M. M. Shmarov, N. A. Nikitenko, L. F. Morozova, E. A. Smolyarchuk, E. V. Kryukov, V. F. Babira, S. V. Borisevich, B. S. Naroditsky, A. L. Gintsburg, Safety and immunogenicity of an rAd26 and rAd5 vector-based heterologous prime-boost COVID-19 vaccine in two formulations: two open, non-randomised phase $1 / 2$

497 7. N. Malkevitch, L. J. Patterson, K. Aldrich, E. Richardson, W. G. Alvord, M. RobertGuroff, A replication competent adenovirus 5 host range mutant-simian immunodeficiency virus (SIV) recombinant priming/subunit protein boosting vaccine regimen induces broad, persistent SIV-specific cellular immunity to dominant and subdominant epitopes in Mamu-A*01 rhesus macaques. $J$ Immunol $170,4281-4289$ (2003).

503 8. J. Zhao, Y. Lou, J. Pinczewski, N. Malkevitch, K. Aldrich, V. S. Kalyanaraman, D. 504 
by repeated administration of Ad5hr-SIVenv/rev and Ad5hr-SIVgag recombinants. Vaccine 21, 4022-4035 (2003).

$508 \quad 9 . \quad$ L. J. Patterson, N. Malkevitch, D. Venzon, J. Pinczewski, V. R. Gomez-Roman, L. 509 Wang, V. S. Kalyanaraman, P. D. Markham, F. A. Robey, M. Robert-Guroff, Protection against mucosal simian immunodeficiency virus SIV(mac251)

10. B. Peng, L. R. Wang, V. R. Gomez-Roman, A. Davis-Warren, D. C. Montefiori, V. S. Kalyanaraman, D. Venzon, J. Zhao, E. Kan, T. J. Rowell, K. K. Murthy, I. adenovirus-human immunodeficiency virus recombinant vaccines are better at eliciting potent cellular immunity and priming high-titer antibodies. Journal of

519 11. J. Zhao, R. Voltan, B. Peng, A. Davis-Warren, V. S. Kalyanaraman, W. G. Alvord, K. Aldrich, D. Bernasconi, S. Butto, A. Cafaro, B. Ensoli, M. Robert-Guroff, Enhanced cellular immunity to SIV Gag following co-administration of $523 \quad 12(2005)$.

524 12. V. R. Gomez-Roman, R. H. Florese, B. Peng, D. C. Montefiori, V. S. 525 Kalyanaraman, D. Venzon, I. Srivastava, S. W. Barnett, M. Robert-Guroff, An 526 adenovirus-based HIV subtype B prime/boost vaccine regimen elicits antibodies 527 mediating broad antibody-dependent cellular cytotoxicity against non-subtype B 528 HIV strains. J Acquir Immune Defic Syndr 43, 270-277 (2006). 
529 13. V. R. Gomez-Roman, G. J. Grimes, Jr., G. K. Potti, B. Peng, T. Demberg, L.

530 Gravlin, J. Treece, R. Pal, E. M. Lee, W. G. Alvord, P. D. Markham, M. Robert$531 \quad$ Guroff, Oral delivery of replication-competent adenovirus vectors is well tolerated 532 by SIV- and SHIV-infected rhesus macaques. Vaccine $\mathbf{2 4 ,}$ 5064-5072 (2006).

533 14. B. Peng, R. Voltan, A. D. Cristillo, W. G. Alvord, A. Davis-Warren, Q. Zhou, K. K. 534 Murthy, M. Robert-Guroff, Replicating Ad-recombinants encoding nonmyristoylated rather than wild-type HIV Nef elicit enhanced cellular immunity. Aids 20, 2149-2157 (2006).

537 15. T. Demberg, R. H. Florese, M. J. Heath, K. Larsen, I. Kalisz, V. S. Kalyanaraman, E. M. Lee, R. Pal, D. Venzon, R. Grant, L. J. Patterson, B. Korioth-Schmitz, A. Buzby, D. Dombagoda, D. C. Montefiori, N. L. Letvin, A. Cafaro, B. Ensoli, M. Robert-Guroff, A replication-competent adenovirus-human immunodeficiency virus (Ad-HIV) tat and Ad-HIV env priming/Tat and envelope protein boosting regimen elicits enhanced protective efficacy against simian/human

545 16. R. Hidajat, P. Xiao, Q. Zhou, D. Venzon, L. E. Summers, V. S. Kalyanaraman, D.

546 C. Montefiori, M. Robert-Guroff, Correlation of vaccine-elicited systemic and mucosal non-neutralizing antibody activities with reduced acute viremia following 548 intrarectal SIVmac251 challenge of rhesus macaques. Journal of virology, (2008).

549 17. C. Morgan, M. Marthas, C. Miller, A. Duerr, C. Cheng-Mayer, R. Desrosiers, J. 550 Flores, N. Haigwood, S. L. Hu, R. P. Johnson, J. Lifson, D. Montefiori, J. Moore, 
M. Robert-Guroff, H. Robinson, S. Self, L. Corey, The use of nonhuman primate models in HIV vaccine development. PLoS medicine 5, e173 (2008).

18. T. Demberg, M. Robert-Guroff, Mucosal immunity and protection against HIVISIV infection: strategies and challenges for vaccine design. International reviews of immunology 28, 20-48 (2009).

19. M. Gurwith, M. Lock, E. M. Taylor, G. Ishioka, J. Alexander, T. Mayall, J. E. Ervin, immunogenicity of an oral, replicating adenovirus serotype 4 vector vaccine for H5N1 influenza: a randomised, double-blind, placebo-controlled, phase 1 study. Lancet Infect Dis 13, 238-250 (2013). replicating vector. Virology 462-463, 158-165 (2014). immune responses generated by single-cycle replicating adenovirus vaccines. Journal of virology 89, 669-675 (2015).

22. S. S. Anguiano-Zarate, W. E. Matchett, P. N. Nehete, J. K. Sastry, A. Marzi, M. A. Barry, A Replicating Single Cycle Adenovirus against Ebola Virus. J. Infectious Dis. in press, (2018).

23. C. M. Crosby, M. A. Barry, Transgene Expression and Host Cell Responses to Replication-Defective, Single-Cycle, and Replication-Competent Adenovirus

572 24. C. M. Crosby, W. E. Matchett, S. S. Anguiano-Zarate, C. A. Parks, E. A. Weaver, 
Vectors Generate Amplified Influenza Vaccine Responses. Journal of virology 91,

575 (2017).

576 25. W. E. Matchett, S. S. Anguiano-Zarate, M. A. Barry, Comparison of systemic and mucosal immunization with replicating Single cycle Adenoviruses. Glob Vaccines Immunol 3, (2018).

579 26. W. E. Matchett, S. S. Anguiano-Zarate, P. N. Nehete, K. Shelton, B. P. Nehete, G. Immune Responses Generated by Systemic and Mucosal Immunization with

27. W. E. Matchett, G. B. R. Malewana, H. Mudrick, M. J. Medlyn, M. A. Barry, Genetic Replicating Single-Cycle Adenoviruses in Rhesus Macaques. Journal of virology

28. W. E. Matchett, S. S. Anguiano-Zarate, M. A. Barry, A Replicating Single Cycle Adenovirus against Clostridium difficile. J. Infectious Dis. in review, (2019).

29. K. R. Bartemes, K. lijima, T. Kobayashi, G. M. Kephart, A. N. McKenzie, H. Kita, IL-33-responsive lineage- CD25+ CD44(hi) lymphoid cells mediate innate type 2 immunity and allergic inflammation in the lungs. J Immunol 188, 1503-1513 (2012).

593 30. L. Karyampudi, C. J. Krco, K. R. Kalli, C. L. Erskine, L. C. Hartmann, K. Goodman, 594 J. N. Ingle, M. J. Maurer, A. Nassar, C. Yu, M. L. Disis, P. J. Wettstein, J. D. Fikes, 595 M. Beebe, G. Ishioka, K. L. Knutson, Identification of a broad coverage HLA-DR 
degenerate epitope pool derived from carcinoembryonic antigen. Cancer Immunol Immunother 59, 161-171 (2010).

598 31. P. M. Folegatti, K. J. Ewer, P. K. Aley, B. Angus, S. Becker, S. Belij-Rammerstorfer, 599 D. Bellamy, S. Bibi, M. Bittaye, E. A. Clutterbuck, C. Dold, S. N. Faust, A. Finn, A. L. Flaxman, B. Hallis, P. Heath, D. Jenkin, R. Lazarus, R. Makinson, A. M. Minassian, K. M. Pollock, M. Ramasamy, H. Robinson, M. Snape, R. Tarrant, M. Voysey, C. Green, A. D. Douglas, A. V. S. Hill, T. Lambe, S. C. Gilbert, A. J. vaccine against SARS-CoV-2: a preliminary report of a phase $1 / 2$, single-blind, randomised controlled trial. Lancet, (2020).

606 32. E. V. Shashkova, S. M. May, M. A. Barry, Characterization of human adenovirus serotypes 5, 6, 11, and 35 as anticancer agents. Virology 394, 311-320 (2009).

608 33. C. M. Crosby, M. A. Barry, Illa deleted adenovirus as a single-cycle genome 609 replicating vector. Virology 462-463, 158-165 (2014).

610 34. M. A. Thomas, J. F. Spencer, W. S. Wold, Use of the Syrian hamster as an animal 611 model for oncolytic adenovirus vectors. Methods Mol Med 130, 169-183 (2007).

612 35. J. Hu, P. Peng, K. Wang, L. Fang, F. Y. Luo, A. S. Jin, B. Z. Liu, N. Tang, A. L. 613 Huang, Emerging SARS-CoV-2 variants reduce neutralization sensitivity to 614 convalescent sera and monoclonal antibodies. Cell Mol Immunol, (2021).

615 36. P. Wang, L. Liu, S. Iketani, Y. Luo, Y. Guo, M. Wang, J. Yu, B. Zhang, P. D. Kwong, 616 B. S. Graham, J. R. Mascola, J. Y. Chang, M. T. Yin, M. Sobieszczyk, C. A. 617 Kyratsous, L. Shapiro, Z. Sheng, M. S. Nair, Y. Huang, D. D. Ho, Increased 
$619 \quad$ Neutralization. bioRxiv, (2021).

620 37. E. C. Sabino, L. F. Buss, M. P. S. Carvalho, C. A. Prete, Jr., M. A. E. Crispim, N. 621 A. Fraiji, R. H. M. Pereira, K. V. Parag, P. da Silva Peixoto, M. U. G. Kraemer, M. 622 K. Oikawa, T. Salomon, Z. M. Cucunuba, M. C. Castro, A. A. de Souza Santos, V. 623 H. Nascimento, H. S. Pereira, N. M. Ferguson, O. G. Pybus, A. Kucharski, M. P. 624 Busch, C. Dye, N. R. Faria, Resurgence of COVID-19 in Manaus, Brazil, despite 625 high seroprevalence. Lancet 397, 452-455 (2021).

626 38. E. A. Weaver, A. M. Rubrum, R. J. Webby, M. A. Barry, Protection against 627 divergent influenza H1N1 virus by a centralized influenza hemagglutinin. PloS one $628 \quad 6$, e18314 (2011).

629 39. E. A. Weaver, M. A. Barry, Low seroprevalent species D adenovirus vectors as 630 influenza vaccines. PloS one 8, e73313 (2013).

631 40. T. V. Nguyen, G. J. Heller, M. E. Barry, C. M. Crosby, M. A. Turner, M. A. Barry, 632 Evaluation of polymer shielding for adenovirus serotype 6 (Ad6) for systemic 633 virotherapy against human prostate cancers. Mol Ther Oncolytics 3, (2016).

634 41. M. A. Turner, S. Middha, S. E. Hofherr, M. A. Barry, Comparison of the Life Cycles 635 of Genetically Distant Species C and Species D Human Adenoviruses Ad6 and 636 Ad26 in Human Cells. Journal of virology 89, 12401-12417 (2015).

637 42. E. A. Weaver, M. L. Hillestad, R. Khare, D. Palmer, P. Ng, M. A. Barry, 638 Characterization of species C human adenovirus serotype 6 (Ad6). Virology 412 , $639 \quad 19-27(2011)$. 
640 43. P. Abbink, A. A. Lemckert, B. A. Ewald, D. M. Lynch, M. Denholtz, S. Smits, L. 641 Holterman, I. Damen, R. Vogels, A. R. Thorner, K. L. O'Brien, A. Carville, K. G. 642 Mansfield, J. Goudsmit, M. J. Havenga, D. H. Barouch, Comparative 643 seroprevalence and immunogenicity of six rare serotype recombinant adenovirus vaccine vectors from subgroups B and D. Journal of virology 81, 4654-4663

646 44. M. D. Dicks, A. J. Spencer, L. Coughlan, K. Bauza, S. C. Gilbert, A. V. Hill, M. G. Cottingham, Differential immunogenicity between HAdV-5 and chimpanzee adenovirus vector ChAdOx1 is independent of fiber and penton RGD loop sequences in mice. Sci Rep 5, 16756 (2015).

45. A. Greinacher, T. Thiele, T. E. Warkentin, K. Weisser, P. A. Kyrle, S. Eichinger,

46. K. L. Muir, A. Kallam, S. A. Koepsell, K. Gundabolu, Thrombotic Thrombocytopenia after Ad26.COV2.S Vaccination. N Engl J Med, (2021). Med, (2021). vector biology and targeting. Current gene therapy 7, 189-204 (2007). 
663 49. P. A. Piedra, G. A. Poveda, B. Ramsey, K. McCoy, P. W. Hiatt, Incidence and 664 prevalence of neutralizing antibodies to the common adenoviruses in children with 665 cystic fibrosis: implication for gene therapy with adenovirus vectors. Pediatrics 101, $666 \quad$ 1013-1019 (1998).

667 
670 Fig. 1. Replication-Defective and Single-Cycle Adenoviruses Expressing SARS-

671 CoV-2 Spike. A) Schematics of replication-defective adenovirus (RD-Ad) spike vaccine

672 construct as compared to single-cycle adenovirus (SC-Ad) spike vaccine construct. In the

673 RD-Ad spike vector, the E1 protein has been removed and the SARS-CoV-2 spike protein

674 has been inserted. In the SC-Ad spike vector, the pIIIA protein has been removed instead

675 of the E1 protein, and the SARS-CoV-2 spike protein has been inserted. B) Western blot

676 of human A549 lung cells infected with SC-Ad vector with GFP-Luciferase (SC-Ad

677 GFPLuc), RD-Ad spike, or SC-Ad spike at doses of $10^{2}$ and $10^{4}$ viral particles per cell.

678 Cells were harvested 24 hours post-infection, and western blot was performed looking for 679 relative levels of SARS-CoV-2 spike protein.

Fig. 2. Kinetics of Spike Antibody Production by RD-Ad and SC-Ad Vaccines after

681 a Single Intranasal or Intramuscular Vaccination. Male Syrian hamsters were 682 immunized at a dose of $10^{9} \mathrm{vp}$, and serum was collected at weeks $2,6,14,26$ after single 683 immunization. Serum was used at 1:1000 dilution to test for SARS-CoV-2 spike IgG 684 antibodies by ELISA. $\left({ }^{* * * *}=p<0.0001,{ }^{* * *}=p<0.0001,{ }^{* *}=p<0.01,{ }^{*}=p<0.05\right)$

685 Fig. 3. Spike Antibody Production by RD-Ad and SC-Ad Vaccines after a Single 686 Intranasal or Intramuscular Vaccination. A) Male Syrian hamsters were immunized at 687 a dose of $10^{9} \mathrm{vp}$, and serum was collected at 26 weeks (6 months) after single 688 immunization. Serum was used at 1:100, 1:500, and 1:1000 dilutions to test for SARS689 CoV-2 spike IgG antibodies by ELISA. B) Male Syrian hamsters were immunized and 690 serum was collected at 6 weeks after single immunization. SARS-CoV-2 neutralization 
691 assay (Genscript) was performed at 1:10, 1:33, and 1:100 serum dilutions comparing RD-

692 Ad spike and SC-Ad spike at intranasal and intramuscular routes of immunization. spike

693 inhibition rate was determined based on the formula provided by Genscript. C, D)

694 Comparison of serum spike IgG antibodies in Syrian hamsters immunized with RD-Ad

695 spike and SC-Ad spike by intramuscular (C) and intranasal (D) routes of administration, 696 analyzed by ELISA at $1: 1000$ serum dilution. $\left({ }^{* * * *}=p<0.0001,{ }^{* * *}=p<0.0001,{ }^{* *}=\right.$ $\left.697 p<0.01,{ }^{*}=p<0.05\right)$

698 Fig. 4. Antibody Binding to Spike RBD and S1 Variants. Week 14 sera from SC-Ad 699 spike or SC-Ad-GL IM hamsters were analyzed for binding to variant RBDs and S1 700 proteins by ELISA at 1:1000, $1: 10,000$, and 1:20,000 dilutions. All levels of significance

701 are shown as compared to the sample's respective SC-Ad GL version. $\left(^{* * *}=p<0.0001\right.$, $\left.702^{* * *}=p<0.0001,{ }^{* *}=p<0.01,{ }^{*}=p<0.05\right)$. More detailed statistical comparisons are shown 703 in Supplemental Fig. 3.

704 Fig. 5. Serum Antibody Production to Spike Protein after Single Intranasal or

705 Intramuscular Administration of SC-Ad-Spike in Mice. Male BALB/c mice were 706 immunized at a dose of $10^{10} \mathrm{vp}$ virus, and serum was collected 2 weeks after single 707 immunization and was tested for SARS-CoV-2 spike IgG antibodies by ELISA. $\left({ }^{* * * *}=\right.$ $\left.708 p<0.0001,{ }^{* * *}=p<0.0001,{ }^{* *}=p<0.01,{ }^{*}=p<0.05\right)$

709 Fig. 6. Mucosal Antibody Production to Spike Protein in Bronchoalveolar Lavages 710 (BALs) after Single Intranasal or Intramuscular Administration of SC-Ad-Spike in

711 Mice. Male BALB/c mice were immunized with $10^{10} \mathrm{vp}$ of SC-Ad-Spike and 712 bronchoalveolar lavage (BAL) fluid was collected at 8 weeks after single immunization. 
713 A) BAL fluid was used at 1:500 dilution to test for SARS-CoV-2 spike IgG and IgA

714 antibodies by ELISA. Plates were read at $450 \mathrm{~nm}$, and all analyses were done by one-

715 way ANOVA. B) SARS-CoV-2 neutralization assay (Genscript) was performed at 1:10

716 dilution of BAL fluid, comparing IN SC-Ad Zika, IN SC-Ad spike and IM SC-Ad spike. spike

717 inhibition rate was determined based on the formula provided by Genscript. $\left(^{* \star *}=\right.$

$\left.718 p<0.0001,{ }^{* * *}=p<0.0001,{ }^{* *}=p<0.01,{ }^{*}=p<0.05\right)$.

719 Fig. 7. Changes in T Cell Populations in Bronchoalveolar Lavages (BALs) after

720 Single Intranasal or Intramuscular Administration of SC-Ad-Spike in Mice. 8 weeks

721 after single immunization of $10^{10} \mathrm{vp}$ of SC-Ad-Spike in BALB/c mice, BAL was performed.

722 Cells were pelleted out of BAL fluid and analyzed by flow cytometry. A) Shows number

723 of CD8 T cells counted that expressed IFN $\gamma$. B) Shows number of CD4 T cells counted

724 that expressed IFN $\gamma$. C) Shows number of CD4 T cells counted that expressed IL-4. ( ${ }^{* * * *}$

$\left.725=p<0.0001,{ }^{* * *}=p<0.0001,{ }^{* *}=p<0.01,{ }^{*}=p<0.05\right)$. 
Figure 1 Mudrick et. al.

A

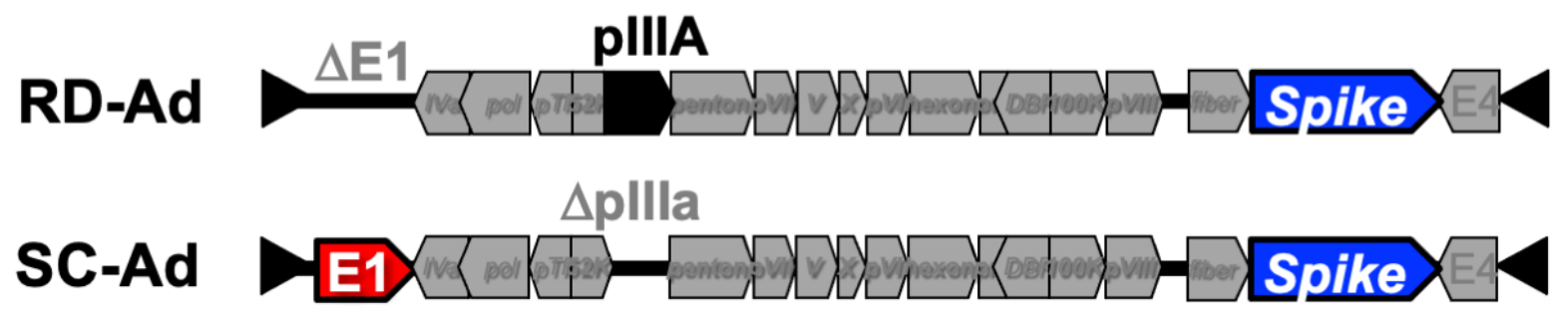

B

\begin{tabular}{c} 
SC-Ad \\
GFPLuc \\
\hline $10^{2} \quad 10^{4}$
\end{tabular}

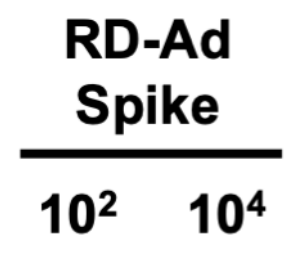

SC-Ad Spike

$10^{2} \quad 10^{4} \mathrm{vp} / \mathrm{cell}$

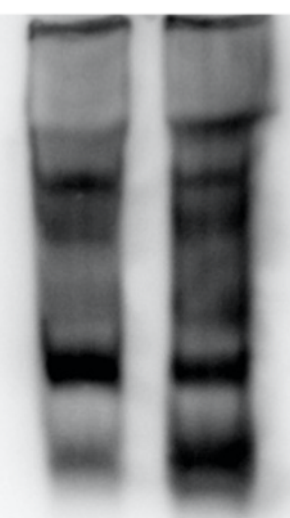


Figure 2 Mudrick et. al.

\section{Male Hamster Serum Antibodies}

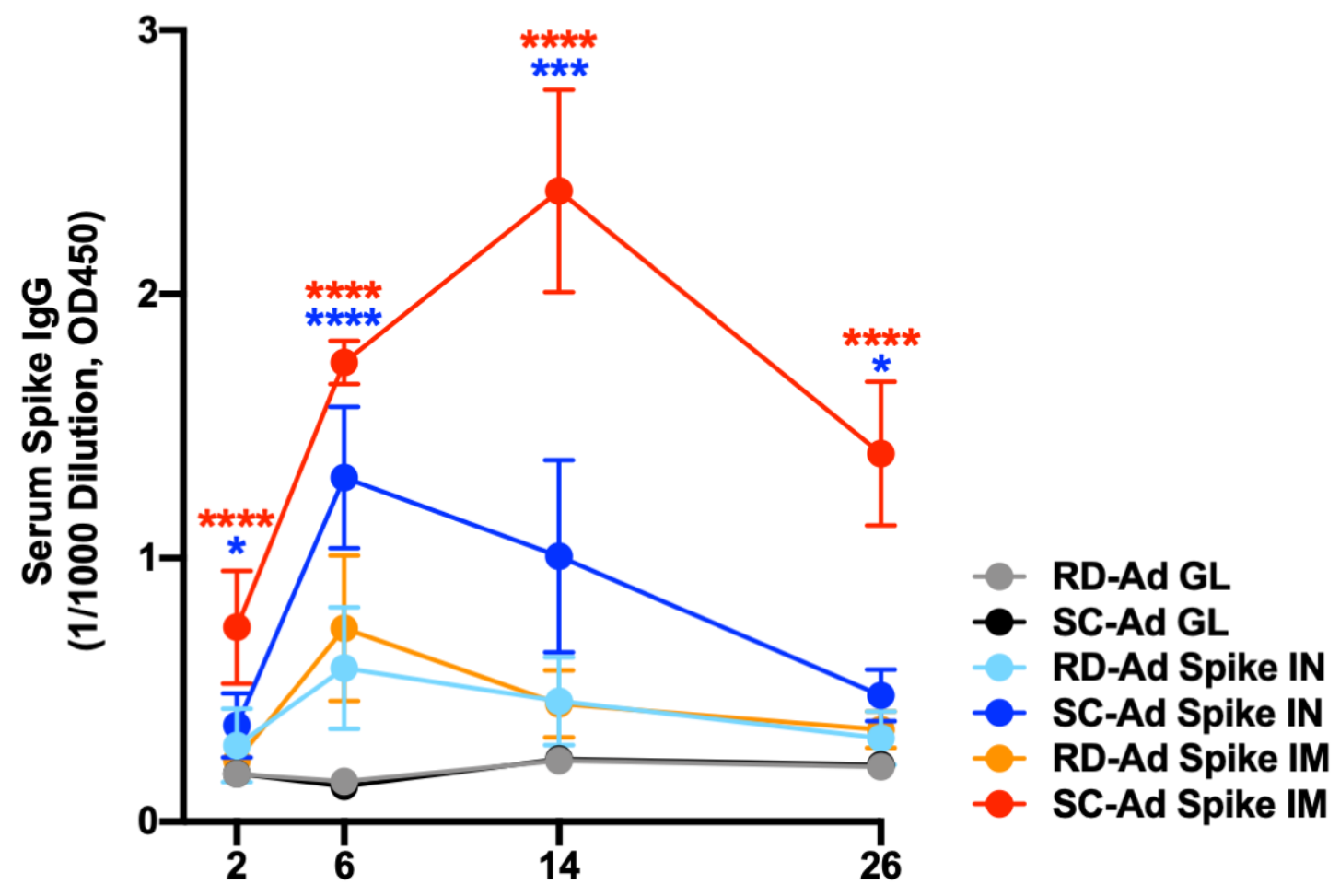

Weeks After Single Immunization 
Figure 3 Mudrick et. al.

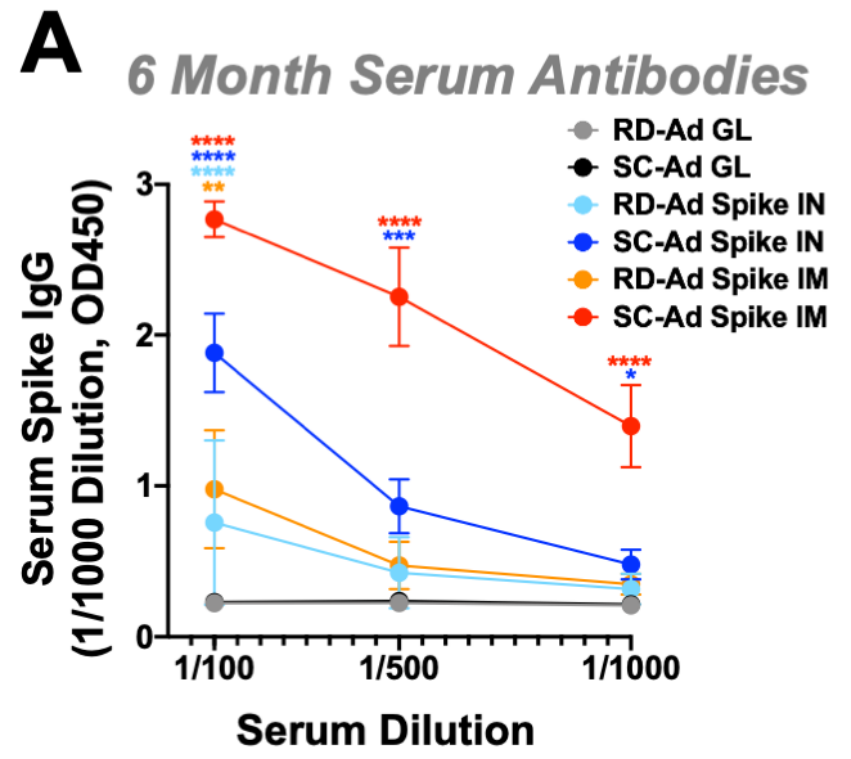

C Intramuscular SC-Ad Spike Serum Antibodies

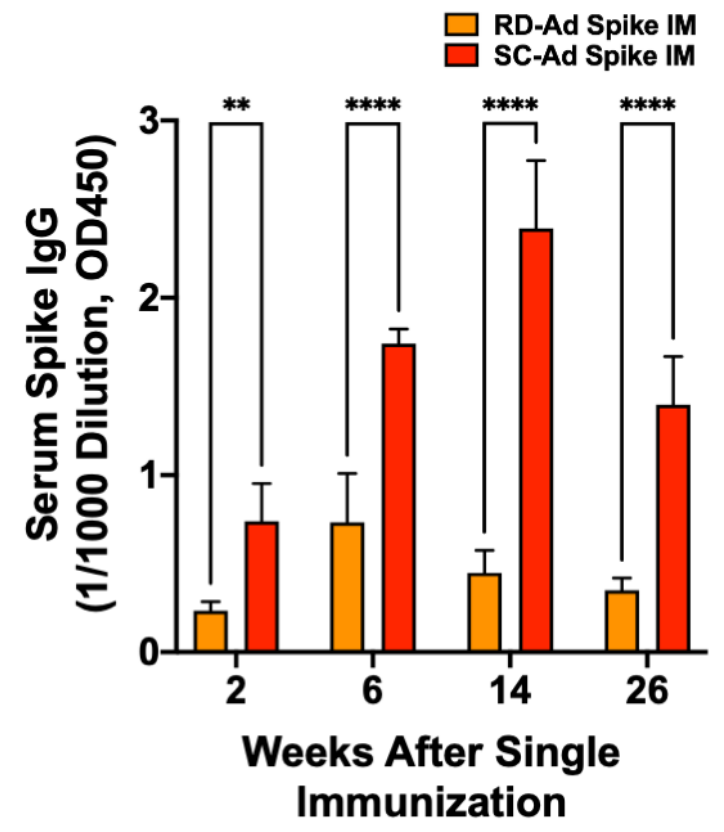

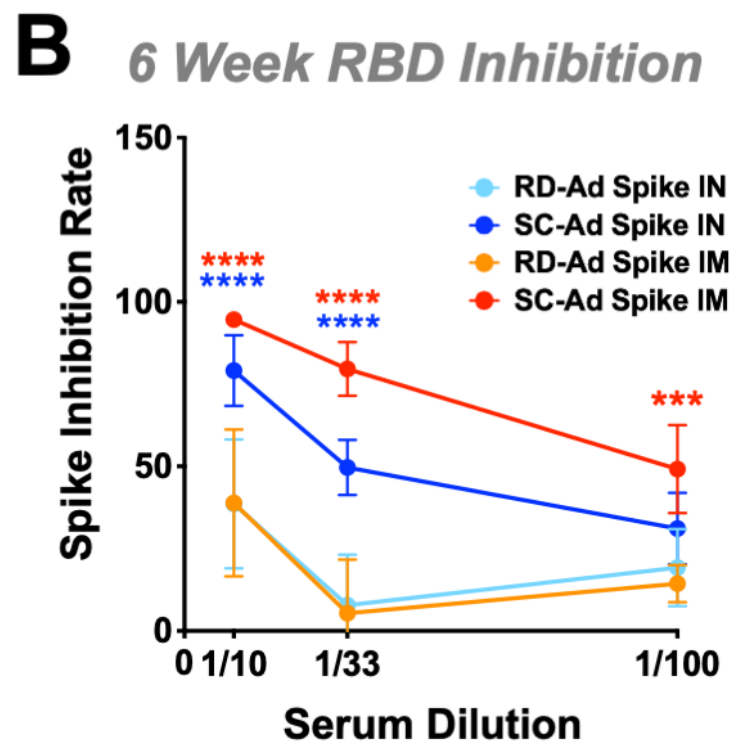

D

Intranasal SC-Ad Spike Serum Antibodies

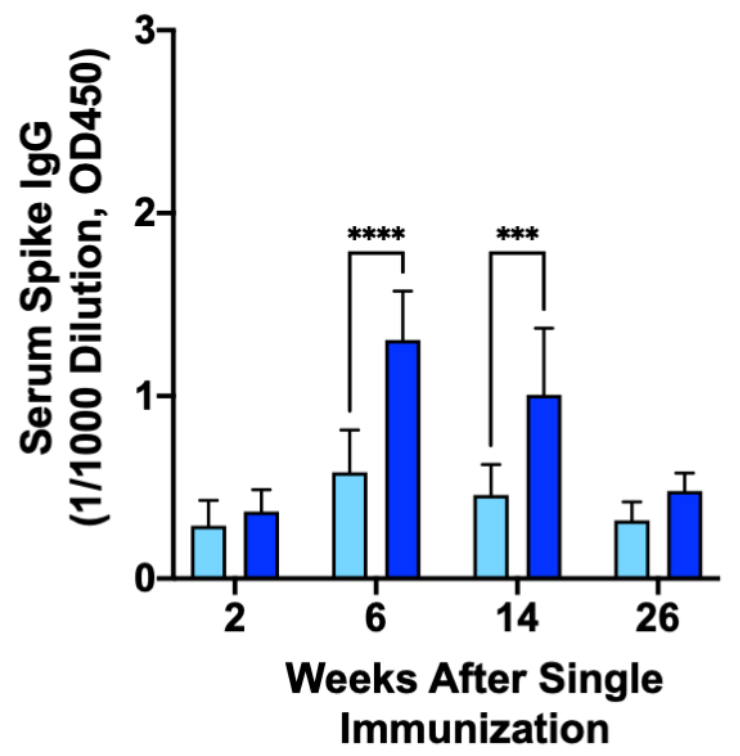




\section{Figure 4 Mudrick et. al.}

\section{SC-Ad Spike IM 14 Week Male Hamster Serum vs. Spike Variants}

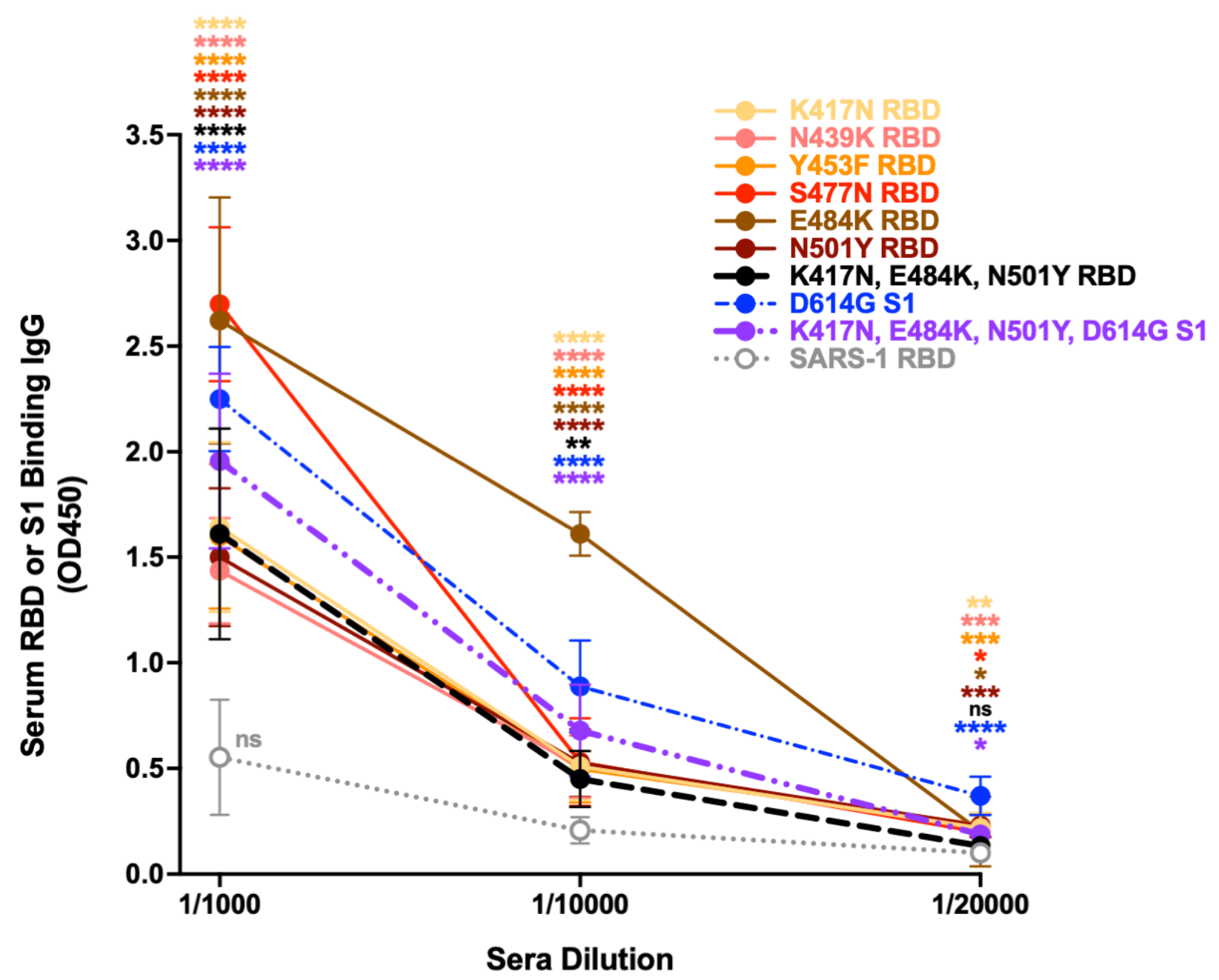


Figure 5 Mudrick et. al.

A 2 Week Serum Antibodies BALB/c Mice

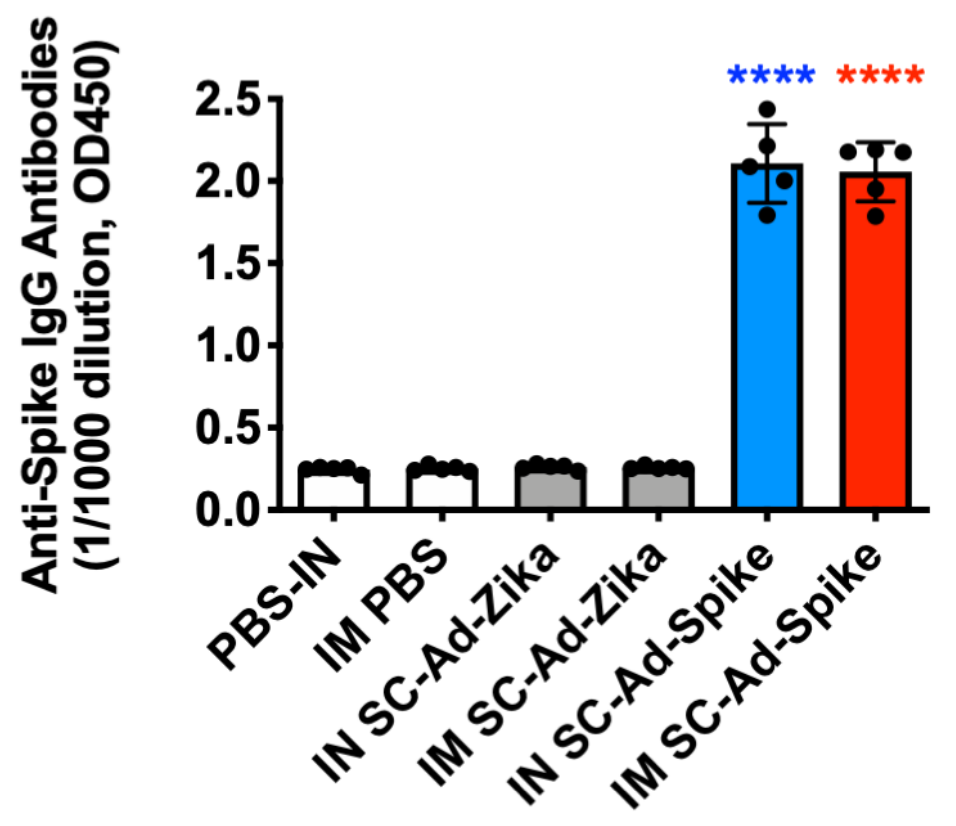


Figure 6 Mudrick et. al.

8 Week BAL Antibodies BALB/c Mice

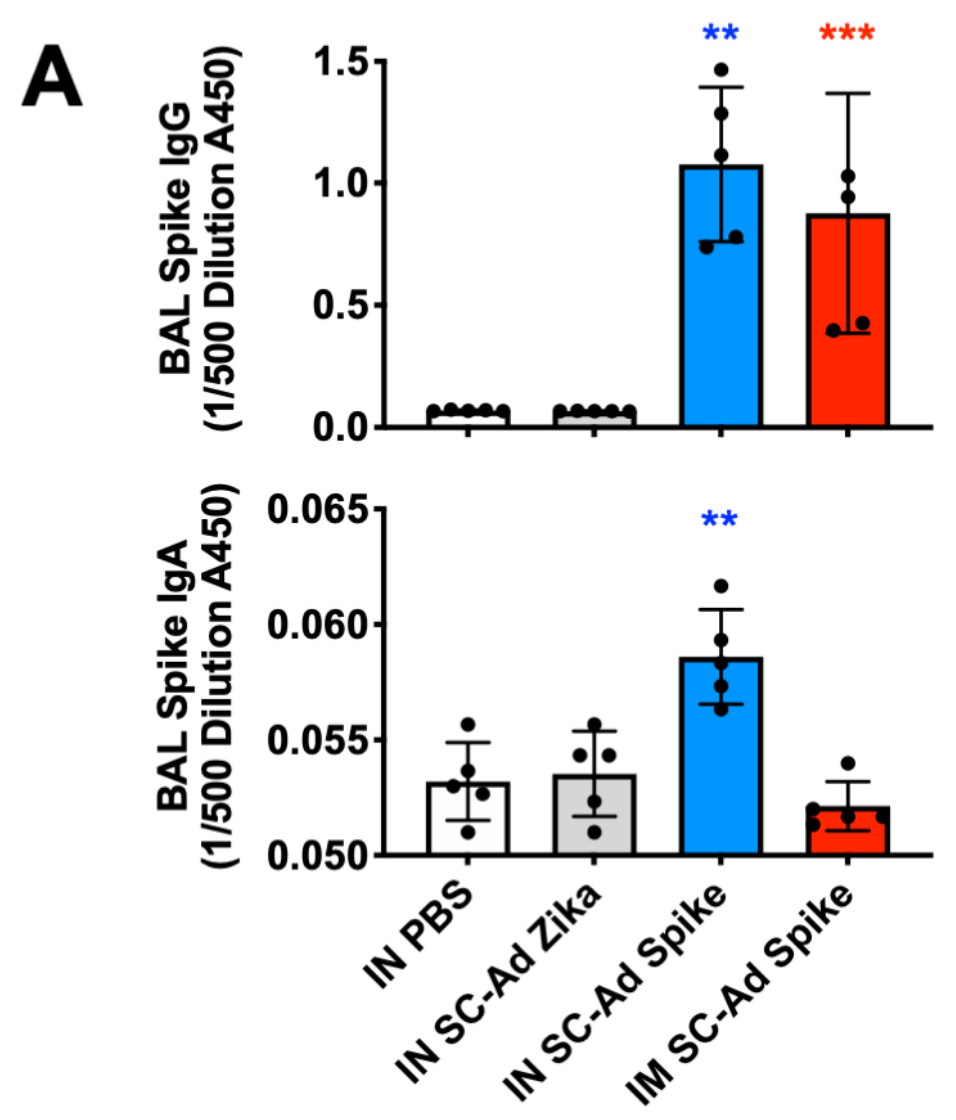

B

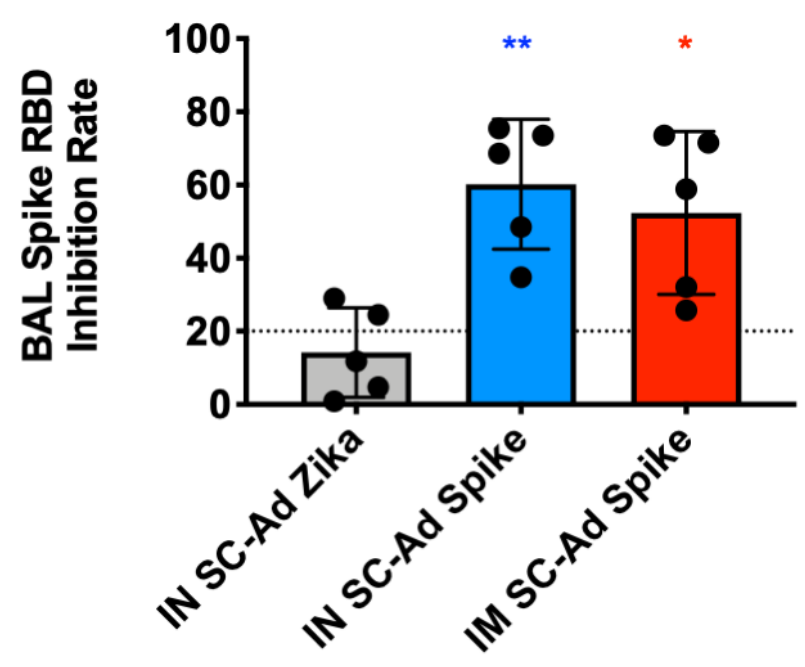


Figure $7 \quad$ Mudrick et. al.
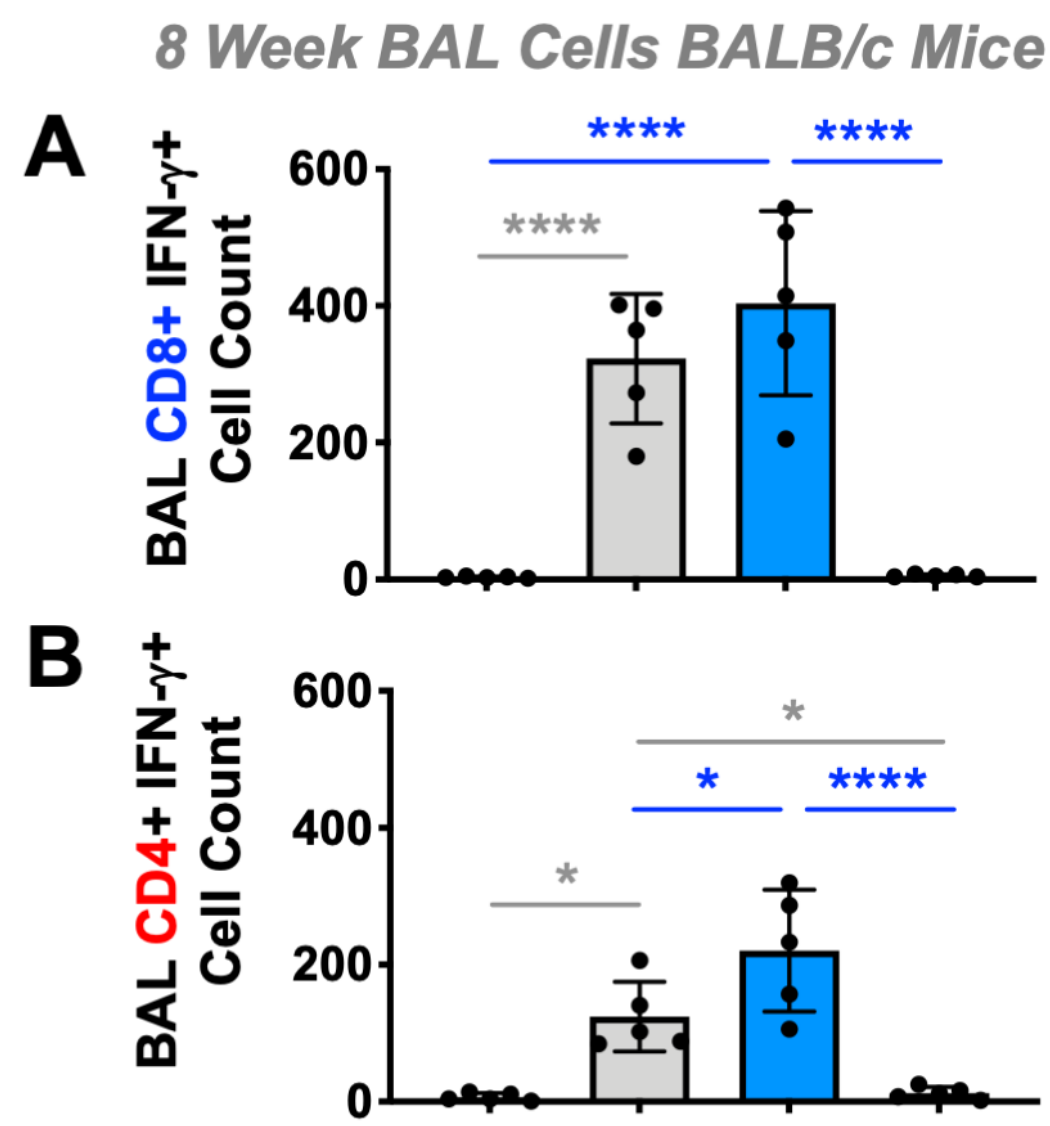

C

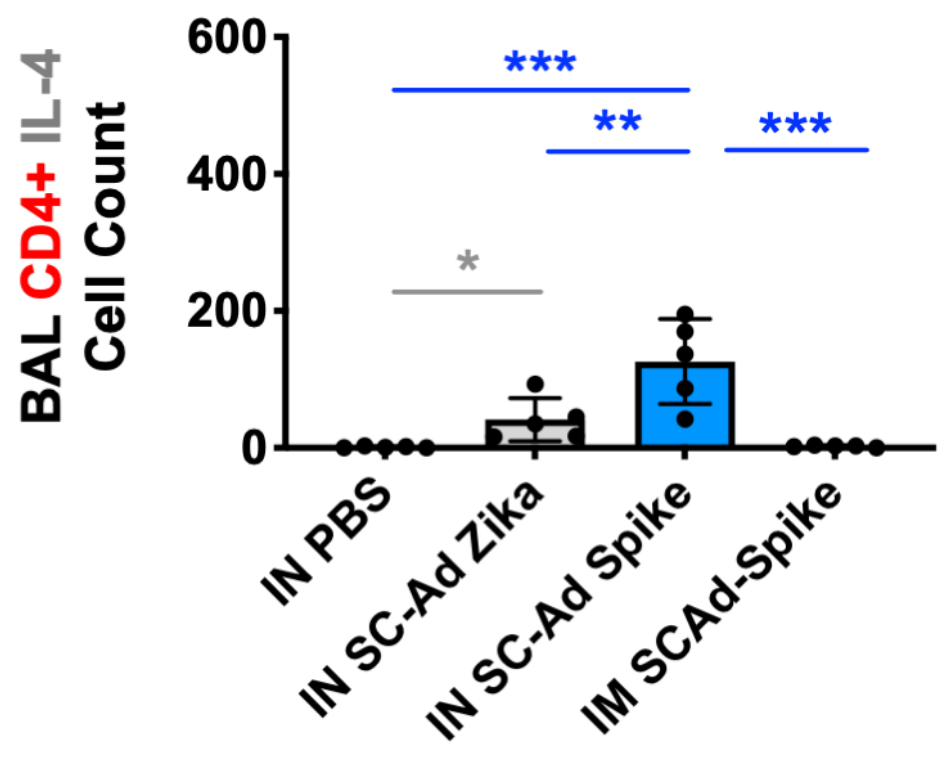

